Bull. Chem. Soc. Ethiop. 2017, 31(2), 201-209.

ISSN 1011-3924

(c) 2017 Chemical Society of Ethiopia and The Authors

Printed in Ethiopia

DOI: http://dx.doi.org/10.4314/bcse.v31i2.2

\title{
PARTIAL LEAST SQUARES-NEAR INFRARED SPECTROMETRIC DETERMINATION OF ETHANOL IN DISTILLED ALCOHOLIC BEVERAGES
}

\author{
Ayalew Debebe ${ }^{1,2}$, Shibru Temesgen $^{3}$, Mesfin Redi-Abshiro $^{1 *}$ and \\ Bhagwan Singh Chandravanshi ${ }^{1}$ \\ ${ }^{1}$ Department of Chemistry, Addis Ababa University, P.O. Box 1176, Addis Ababa, Ethiopia \\ ${ }^{2}$ Department of Chemistry, Haramaya University, P.O. Box 138, Dire Dawa, Ethiopia \\ ${ }^{3}$ Department of Statistics, Addis Ababa University, P.O. Box 1176, Addis Ababa, Ethiopia
}

(Received November 28, 2016; revised September 26, 2017)

\begin{abstract}
In this study, using near infrared (NIR) spectrometry-partial least squares (PLS) calibration model was used for the determination of ethanol content in distilled alcoholic beverages. In NIR, 1660-1720 nm, the PLS modeling and analysis made use of 24 standards which contain $2-15 \%(w / w)$ ethanol with $0.1-1 \%(w / w)$ methanol. One-half was used for calibration and the other half for validation. Derivative, mean centering and subtracting minimum value were used as data treatment techniques for noise reduction and baseline correction. Mean centering has given the best partial least squares model with $\mathrm{R}^{2}=0.999$ and root mean square error of prediction $($ RMSEP $)=0.06$ for ethanol and $\mathrm{R}^{2}=0.929$ and $\mathrm{RMSEP}=0.08$ for methanol, respectively. The percentage recovery obtained for ethanol and methanol ranges from $97-98 \%(w / w)$. The developed method produced good agreement with reference method, gas chromatography.
\end{abstract}

KEY WORDS: Distilled alcoholic beverages, Ethanol, Methanol, Near infrared spectrophotometry, Partial least squares, Chemometry, Gas Chromatography

\section{INTRODUCTION}

Ethanol is the major constituent of alcoholic beverages especially for distilled alcoholic beverages. The analytical control of ethanol is required for health and economic reasons, owing to the special taxes imposed on alcohol $[1,2]$. With methanol, the high toxicity following its ingestion, inhalation or percutaneous absorption makes necessary its careful control in beverages and also in cosmetics [1].

The level of alcohol in alcoholic beverages has been determined using densitometry and pychnometry $[3,4]$, or by other analytical techniques such as refractive index $[3,4]$, oxidation of distillate [3, 4], dichromate oxidation [3, 4], enzymatic [3], biosensor [3, 5], potentiometry [3, 6], gas chromatography [3, 7], capillary electrophoresis [3], high performance liquid chromatography [3], beer analyzer [3,7], colorimetric method [8] and flow injection analysis [9-11]. However, the techniques employed are tedious, expensive, time consuming and require sample preparation [12].

Infrared spectroscopy based methods are recently emerging because of their versatility, efficiency, being cost effective, fast and non-invasiveness [13, 14]. However, there are two major problems. First of all, the components under investigation are chemically very similar and therefore display similar IR absorption characteristics. The second problem is that the dominating absorption of ethanol, water and in some cases, sugars strongly influences the determination of one of these components in the presence other two components [15]. Conversely, since chemometrics provides powerful tools for extracting analytical information from a large amount of data produced [1] infrared spectroscopy combined with multivariate data analysis has been developed for the rapid quantitative analysis of the most important compounds in wines [16], spirit drinks and beer in official food control [17]. Near infrared (NIR) and mid infrared (MIR) are the two techniques which have been used, with NIR methods dominating [1, $18]$.

*Corresponding author. E-mail: mesfinredi@yahoo.com

This work is licensed under the Creative Commons Attribution 4.0 International License 
NIR spectral region from 714 to $2500 \mathrm{~nm}$ [19] was employed for simultaneous determination of methanol and ethanol contents in gasoline and fermented beverages $[17,19]$. But, the PLS regression models were developed using the spectral range from 1105 to $1682 \mathrm{~nm}$ [19], 2000 to $10,800 \mathrm{~nm}$ [16] and 2220 to $2354 \mathrm{~nm}$ [20] in different studies.

The band between 1120 and $1270 \mathrm{~nm}$ refers to the $2^{\text {nd }}$ overtone of the $\mathrm{C}-\mathrm{H}$ bond stretching from the diverse hydrocarbons and the alcohols. Another band, also wide, between 1350 and $1670 \mathrm{~nm}$, results from the overlapping of two absorption bands. The first band, located between 1350 and $1550 \mathrm{~nm}$, is related to first overtone of the combination band from $\mathrm{C}-\mathrm{H}+\mathrm{C}-\mathrm{H}$ and $\mathrm{C}-\mathrm{H}+\mathrm{C}-\mathrm{C}$ stretching and, the second band, between 1400 and $1670 \mathrm{~nm}$, is related to the first overtone of $\mathrm{O}-\mathrm{H}$ stretching from the alcohols (methanol and ethanol) [17, 19]. In the region below $1449 \mathrm{~nm}$, methyl $\left(-\mathrm{CH}_{3}\right)$ and methylene $\left(-\mathrm{CH}_{2}-\right)$ groups absorption, coming from the different hydrocarbons and alcohols present in the beverages, are observed [17, 19]. It is also possible to observe, absorption above $1650 \mathrm{~nm}$ refers to aromatic hydrocarbons first overtone of $\mathrm{C}-\mathrm{H}+\mathrm{C}-\mathrm{H}$ and $\mathrm{C}-\mathrm{H}+\mathrm{C}-\mathrm{C}$ stretching, which is overlapped by absorptions of $\mathrm{O}-\mathrm{H}$ stretching of alcohols [17, 19]. At $1790 \mathrm{~nm}$ the first $\mathrm{C}-\mathrm{H}$ stretching overtone occurs. Another strong band characteristic of alcoholic beverages occurs at $1950 \mathrm{~nm}$. This band is related to the combination of the moves of stretching and angular bending of the water $\mathrm{OH}$. In the vicinity of $1160 \mathrm{~nm}$, carbonilic and aromatic compounds usually exhibits its second overtone absorption [17].

PLS-FTIR has been employed to determine sucrose in fruit juices and glucose, total protein, cholesterol, urea and uric acid in blood, in pharmaceutical analysis; it allows the simultaneous determination of paracetamol, acetylsalicylic acid, caffeine, etc [1] and for simultaneous determination of methanol and ethanol contents in gasoline [19, 21] and beverages [21, 22].

Fourier transform mid-infrared spectrophotometry (FT-MIR), 1180-950 $\mathrm{cm}^{-1}$, and nearinfrared spectrophotometry (NIR), 1720-1660 nm, have been used complementarily for the direct determination of ethanol and methanol in distilled alcoholic beverages [23]. In midinfrared, ethanol and methanol were identified separately; hence, it has been used to confirm the absence or presence of methanol. In the absence of methanol, both methods were used to determine the alcoholic strength independently; however, near-infrared was used without diluting the samples. The reported methods are simple, fast, precise, and accurate [23].

The direct determination of ethanol in traditional fermented alcoholic beverages using mid infrared spectroscopy with partial least squares regression (MIR-PLS) has also been reported [24]. The MIR-PLS predicted values were found to be in excellent agreement with gas chromatographic measurements. The matrix effects of the samples were found negligible. The method was found appropriate to quantify ethanol in fermented alcoholic beverages. The developed method was simple, fast, precise and accurate. Moreover, no sample preparation was required at all. However, it should be noted that the present procedure is probably not usable for regulatory purposes (e.g. controlling labelling) [24].

The literature survey revealed that FT-MIR and MIR-PLS have been used for the determination of ethanol in the beverages. However, there is no any report on the simultaneous determination of ethanol and methanol by the PLS-NIR method. Thus, the main aim of this work is to develop PLS calibration models for the simultaneous determination of the ethanol and methanol contents of the distilled beverages using NIR, and comparing the result obtained by the reference method, gas chromatography (GC).

\section{EXPERIMENTAL}

\section{Preparation of standard solutions}

Twenty-four standard samples within the range of $2-15 \%$ ethanol and $0.1-1.0 \%$ methanol, respectively, were prepared for calibration. The mixture standard solutions were 2, 6, 10 and $15 \%(w / w)$ ethanol with $0.1,0.2,0.4,0.6,0.8$ and $1 \%(w / w)$ of methanol for their simultaneous 
determination. These concentration ranges were selected on the basis that methanol concentration does not exceed more than $1 \%$ in real samples. While $1-50 \%$ ethanol standard solutions were prepared for the determination of ethanol in the absence of methanol. All the standard solutions were prepared using methanol (99.7\%, Sigma-Aldrich, France) and ethanol (99.99\%, Fisher scientific, UK) in distilled water. Horizontal type ATR accessory with zinc selenide (ZnSe) crystal was employed for spectral measurements. Spectra were collected in the spectra region between 1720 and $1660 \mathrm{~nm}$ with air and water as backgrounds. For the determination of ethanol in the real samples, $10 \mathrm{~mL}$ of the samples were diluted to $50 \mathrm{~mL}$ in distilled water.

For GC-FID standard solutions ranges from 1-50\% $(w / w)$ were prepared from $99.99 \%(v / v)$ ethanol in 5\% n-propanol. For the determination of ethanol, $10 \mathrm{~mL}$ of the samples were diluted to $50 \mathrm{~mL}$ in distilled water and n-propanol was used as an internal standard. n-Propanol was added before dilution.

Instrumentation and data analysis procedure

UV-Vis spectrophotometer (Lambda 950, Perkin Elmer) and gas chromatography with flame ionization detector and ECTm-5 capillary column (GC 1000, Dani) were used to determine ethanol and methanol in the samples and standards. Density meter (DMA 4500M, Anton Paar) was used to measure the density of methanol and ethanol standard solutions to convert $w / w \%$ to $v / v \%$. Quartz cuvette was used as sample holder for NIR spectrometry. Balance (Adventurer, OHAUS) was used to weight the samples and standard solutions.

The working conditions selected for GC-FID were $3 \mu \mathrm{L}$ injection volume, oven temperature initially at $75^{\circ} \mathrm{C}$ for $2 \mathrm{~min}$, and then increased to the final temperature of $80{ }^{\circ} \mathrm{C}$ in $5 \mathrm{~min}$ at rate of $1{ }^{\circ} \mathrm{C} / \mathrm{min}, 210{ }^{\circ} \mathrm{C}$ injection port temperature, 0.5 bar pressure, carrier gas flow rate 1.4 $\mathrm{mL} / \mathrm{min}$ and $300{ }^{\circ} \mathrm{C}$ detector temperature. Internal standard is commonly used for the quantification of ethanol using GC-FID. Thus, n-propanol was used as an internal standard since it was not found in the samples. It gave a well separated peak from that of ethanol. The calibration curve was constructed using peak area ratio (ethanol : n-propanol) vs concentration of ethanol, $\%(w / w)$. The ethanol concentration of the real samples were determined using the calibration curve, $\mathrm{y}=0.14183 \mathrm{x}+0.00743$ having $\mathrm{R}^{2}=0.9999$.

The calibration model was obtained by the MATLAB 7.8.0 software. In the ethanol determination, the PLS/NIR calibration made use of 12 standards while the other 12 standards were used for validation.

\section{RESULTS AND DISCUSSION}

\section{Spectra of methanol and ethanol}

The spectra of mixture of ethanol and methanol showed only one peak (Figure 1). The two components (methanol and ethanol) peaks showed an overlap. Here, a single effect on one component has been observed as an effect of the total. This is because both of them (methanol and ethanol) involve in the absorbance of $\mathrm{O}-\mathrm{H}$ stretch (Figure 1) $[17,19]$. Therefore, NIR requires multivariate technique to resolve these collinear data. Accordingly, the partial least squares method was developed and compared with reference method, gas chromatography. 


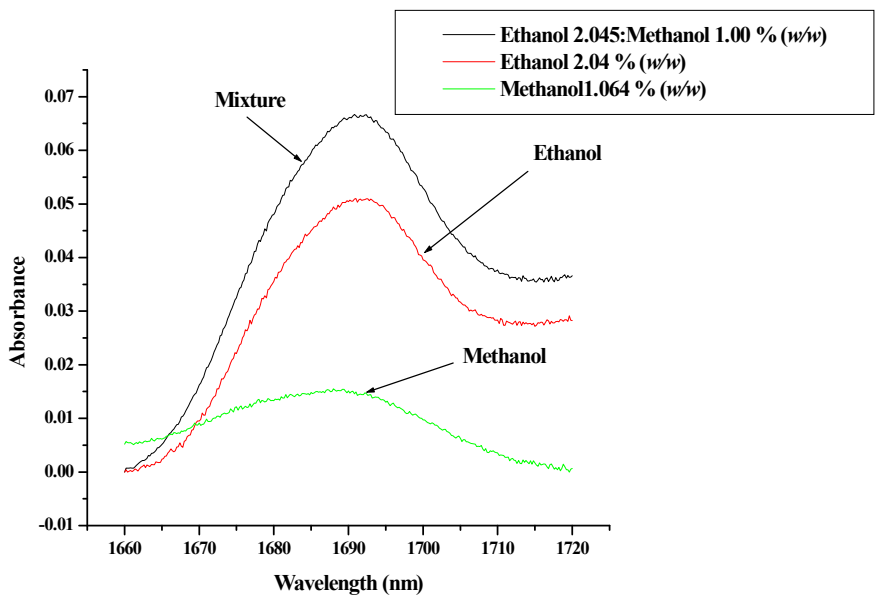

Figure 1. NIR spectra of $2.04 \%$ ethanol and $1.0 \%$ methanol mixture, $2.04 \%$ pure ethanol and $1.064 \%$ pure methanol.

Wavelength selection

Wavelength selection is important for any calibration to be accurate. Spectral regions were selected by the spectral distribution of the relative standard deviation in concentration $(\mathrm{Sc} / \mathrm{c})$ [21] and shorter spectral range [20]. In this study, the range 1660-1720 nm was selected due to the fact that the solvent (water) does not show any absorbance, the intensity of the source is sufficient; the obtained peaks are comparably sharp in selected region having short spectral range and no study has been reported in the selected region. In addition, the $\mathrm{O}-\mathrm{H}$ stretching of alcohols may not overlap with aromatic hydrocarbons first overtone above $1650 \mathrm{~nm}$, because the beverages are distilled [17, 19]. Therefore, the partial least squares model was selected to overcome the problem associated with overlap of peaks (Figure 1). The spectral range selected was $1660-1720 \mathrm{~nm}$ and the data acquisition interval was $0.2 \mathrm{~nm}$. Accordingly 301 data points were collected.

The partial least squares model

\section{Score plot and partial least squares components}

The score plot of the standards in the region is shown in the Figure 2. In the score plot the standards are projected onto new variables, called principal components. Since these projections have been normalized, values in the plot reflect how similar each standard is to a given principal component. In the score plots there are no groups of standards, which show higher similarity in the standards used for calibration (Figure 2). This confirmed that the calibration set has a good distribution.

The contribution of the partial least square components vary depends upon the regions and types of components selected. Similarly, in NIR the first principal component contributed to almost all of the variation. The contribution of the second component is very limited (Figure 3). In this study both components of the mixture; ethanol and methanol have showed the same pattern of partial least components. But, as it is seen in Figure 3, the first principal component 
has contributed to almost all of the variation $(99.86 \%)$ while the other components have negligible contribution. Even though the other components have very little contribution, six components were chosen to construct PLS-NIR model to have the total contribution to $100 \%$ which has a great match with the original data.

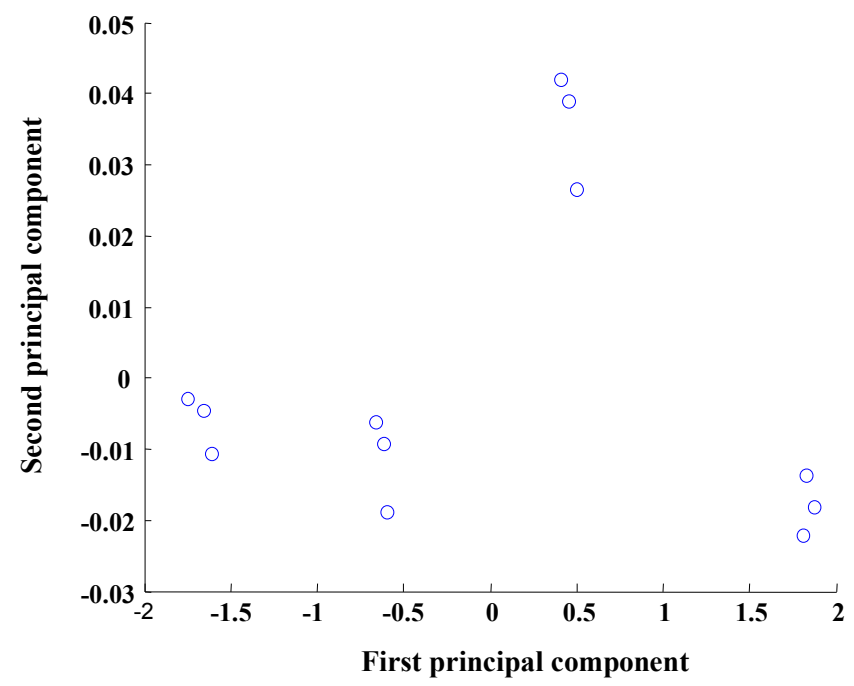

Figure 2. Principal component scatter plot of the NIR calibration set. The mixture standard solutions were $2,6,10$ and $15 \%(w / w)$ ethanol with $0.1,0.2,0.4,0.6,0.8$ and $1 \%(w / w)$ of methanol.

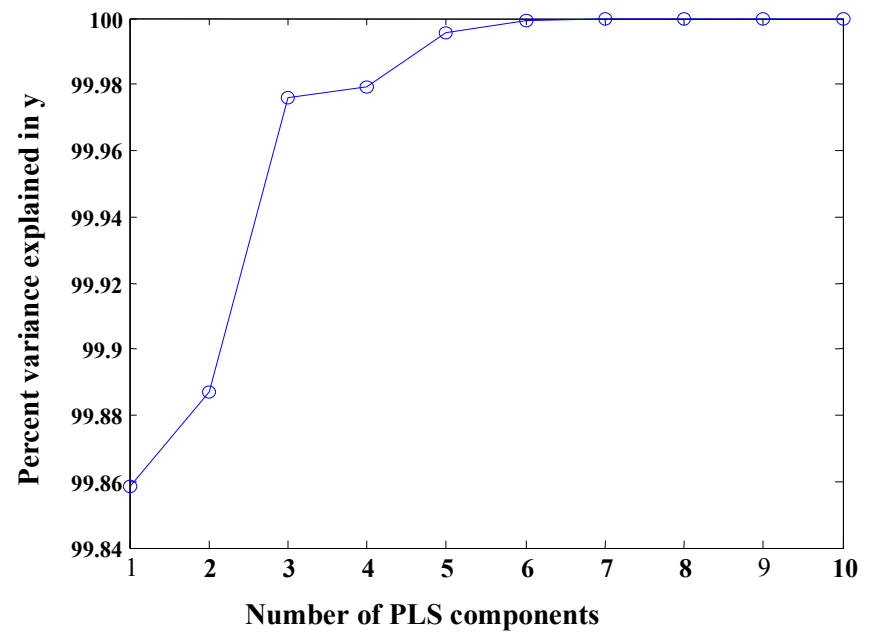

Figure 3. Partial least squares components for ethanol in NIR. 


\section{Pretreatment methods}

Pretreatment methods are various in numbers. They have been applied for different purposes such as for noise reduction, base line correction, etc [25]. Based on this some data pretreatment methods have been applied, the results obtained are indicated in the Table 1. All of them are best for ethanol in both calibration and validation sets. In spite, they differ by the data they have for methanol. Among the methods, mean centering has more $R$ squared value, $R^{2}=0.929$ and minimum prediction error, RMSEP $=0.08$. Therefore, this one has taken to determine the concentration of ethanol and methanol in the real samples.

Table 1. Results of PLS-NIR calibration models for the determination of ethanol and methanol in distilled alcoholic beverages.

\begin{tabular}{|l|l|c|c|c|c|c|}
\hline \multirow{2}{*}{ Data treatment } & Component & \multirow{2}{*}{$\begin{array}{c}\text { Validation } \\
\text { method (PC) }\end{array}$} & \multicolumn{2}{|c|}{ Calibration } & \multicolumn{2}{|c|}{ Validation } \\
\cline { 4 - 7 } & & 6 & $\mathrm{R}^{2}$ & $\mathrm{RMSEE}$ & $\mathrm{R}^{2}$ & RMSEP \\
\hline \multirow{3}{*}{ Subtracting minimum } & Ethanol & 6 & 1.0000 & 0.0011 & 0.999 & 0.1 \\
\cline { 2 - 7 } & Methanol & 6 & 0.9986 & 0.0001 & 0.926 & 0.07 \\
\hline \multirow{2}{*}{ Mean centering } & Ethanol & 6 & 1.0000 & 0.0002 & 0.999 & 0.06 \\
\cline { 2 - 7 } & Methanol & 6 & 0.9997 & 0.0000 & 0.929 & 0.08 \\
\cline { 4 - 7 } & Ethanol & 6 & 1.0000 & 0.0000 & 0.999 & 0.17 \\
\cline { 2 - 7 } & Methanol & 6 & 0.9999 & 0.0000 & 0.067 & 0.28 \\
\hline
\end{tabular}

PC: number of principal components; RMSEE: root mean square error of estimation, RMSEP: root mean square error of prediction.

\section{Method validation}

Validation of the developed model was done using a validation set that contains 12 synthetic samples. The amounts of the measured and predicted ethanol using the models are indicated in Table 2 and the $\mathrm{R}^{2}$ and the RMSEP are shown in Table 1 . The prediction errors of the model for ethanol and methanol contents are 0.06 and $0.08 \%(w / w)$. In addition, the predicted amounts were evaluated and compared with the measured values at $99 \%$ confidence level. The results obtained indicated that no significance difference between them. And also the average standard deviation for ethanol and methanol were 0.08 and $0.09 \%(w / w)$, respectively. Each sample was analyzed in triplicate and standard deviation was calculated. The average standard deviation was obtained as the mean of standard deviations of the 12 samples. Differences between the measured and predicted values (the error) were in the range $(0.00-0.14 \%, w / w)$.

Table 2. Amount of ethanol and methanol in the validation set samples.

\begin{tabular}{|c|c|c|c|c|c|c|}
\hline \multirow{2}{*}{ Sample } & \multicolumn{2}{|c|}{$\begin{array}{c}\text { Amount measured } \\
(\%, w / w)\end{array}$} & \multicolumn{2}{c|}{$\begin{array}{c}\text { Amount obtained (predicted) } \\
\text { using the model }(\%, w / w)\end{array}$} & \multicolumn{2}{c|}{$\begin{array}{c}\text { Difference between the measured } \\
\text { and predicted values }(\%, w / w)\end{array}$} \\
\cline { 2 - 7 } & Ethanol & Methanol & Ethanol & Methanol & Ethanol & Methanol \\
\hline 1 & 2.02 & 0.14 & 1.99 & 0.11 & 0.03 & 0.03 \\
\hline 2 & 2.04 & 0.42 & 2.04 & 0.42 & 0.00 & 0.00 \\
\hline 3 & 2.06 & 0.85 & 2.12 & 0.73 & 0.06 & 0.12 \\
\hline 4 & 6.04 & 0.15 & 6.06 & 0.25 & 0.02 & 0.10 \\
\hline 5 & 6.05 & 0.43 & 6.01 & 0.43 & 0.04 & 0.00 \\
\hline 6 & 6.03 & 0.83 & 5.99 & 0.97 & 0.04 & 0.14 \\
\hline 7 & 10.02 & 0.12 & 9.88 & 0.15 & 0.14 & 0.03 \\
\hline 8 & 10.03 & 0.44 & 10.15 & 0.34 & 0.12 & 0.10 \\
\hline 9 & 10.02 & 0.81 & 10.06 & 0.77 & 0.04 & 0.04 \\
\hline 10 & 15.08 & 0.14 & 15.07 & 0.16 & 0.01 & 0.02 \\
\hline 11 & 15.02 & 0.50 & 14.95 & 0.59 & 0.07 & 0.09 \\
\hline 12 & 15.09 & 0.88 & 15.08 & 0.81 & 0.01 & 0.07 \\
\hline
\end{tabular}

Bull. Chem. Soc. Ethiop. 2017, 31(2) 
Real sample analysis

Three commercial alcoholic beverages, Stolichnaya Vodka, Red Label and White Horse and three traditional beverages, Cereal, Yekosso and Yegibto Arekes were procured from the market for analysis. Ethanol in real samples was quantified using PLS-NIR calibration model and GCFID. The conversion factor for converting $\%(\mathrm{w} / \mathrm{w})$ into $\%(\mathrm{v} / \mathrm{v})$ of ethanol described by Debebe et al. [23] was used to convert $\%(\mathrm{w} / \mathrm{w})$ into $\%(\mathrm{v} / \mathrm{v})$ of ethanol in the real samples. The $\%(\mathrm{v} / \mathrm{v})$ of ethanol was obtained by multiplying the $\%(\mathrm{w} / \mathrm{w})$ with conversion factor 1.2188 [23]. The results obtained by GC-FID and PLS-NIR were statistically analyzed with one-way ANOVA using Origin Lab-Origin 8 at $99 \%$ confidence level. The comparison of results pertaining ethanol concentration between reference analysis, GC-FID and the PLS-NIR model is illustrated in Table 3 and Figure 4.

Table 3. Ethanol content in real distilled alcoholic beverage samples as determined by PLS-NIR and compared to the reference method, GC-FID values and the reported method [23].

\begin{tabular}{|c|l|c|c|c|c|c|}
\hline \multirow{2}{*}{ No. } & Samples & \multicolumn{2}{|c|}{$\begin{array}{c}\text { Ethanol in \% }(w / w) \\
\text { found by this study }\end{array}$} & \multicolumn{2}{c|}{$\begin{array}{c}\text { Ethanol in \% }(v / v) \\
\text { found by this study }\end{array}$} & \multirow{2}{*}{$\begin{array}{c}\text { Ethanol in \% (v/v) } \\
\text { reported in [23] }\end{array}$} \\
\cline { 3 - 6 } & & PLS-NIR & GC-FID & PLS-NIR & GC-FID & \\
\hline 1 & Yegibto Areke & $40.12 \pm 0.05$ & $38.89 \pm 0.05$ & $48.90 \pm 0.06$ & $47.40 \pm 0.06$ & 48.7 \\
\hline 2 & Red label & $32.79 \pm 0.12$ & $33.55 \pm 0.68$ & $39.96 \pm 0.15$ & $40.89 \pm 0.83$ & 39.1 \\
\hline 3 & S. Vodka & $33.17 \pm 0.09$ & $34.33 \pm 0.32$ & $40.43 \pm 0.11$ & $41.84 \pm 0.39$ & 39.4 \\
\hline 4 & Cereal Areke & $40.52 \pm 0.03$ & $39.62 \pm 1.79$ & $49.39 \pm 0.04$ & $48.29 \pm 2.18$ & 48.2 \\
\hline 5 & White Horse & $30.51 \pm 0.38$ & $31.68 \pm 0.74$ & $37.19 \pm 0.46$ & $38.61 \pm 0.90$ & -- \\
\hline 6 & Yekosso Areke & $39.88 \pm 0.11$ & $39.36 \pm 0.42$ & $48.61 \pm 0.13$ & $47.97 \pm 0.51$ & 48.8 \\
\hline
\end{tabular}

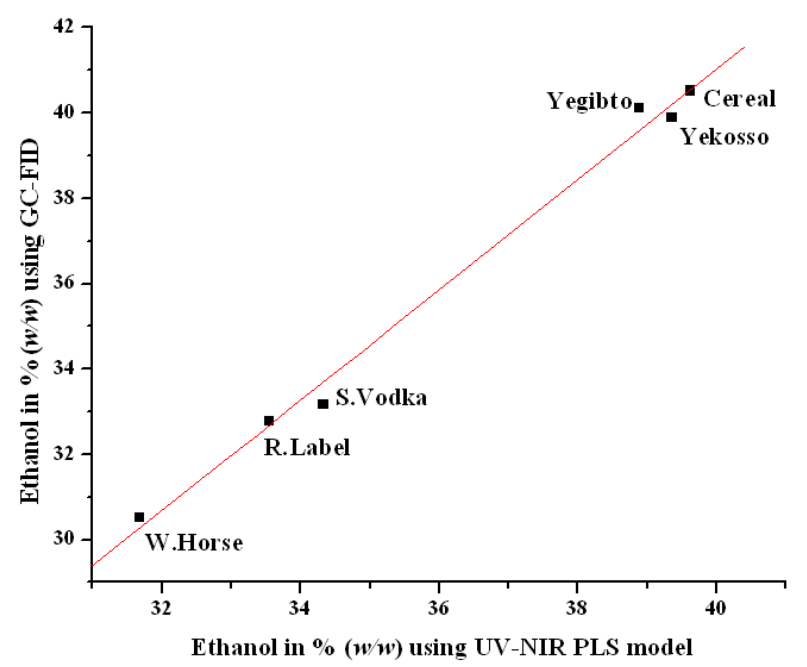

Figure 4. Predicted values versus reference values of ethanol.

Table 3 displays the amount of ethanol determined by the proposed and the reference methods. The obtained result found that the techniques are comparable and did not show any significant difference at $99 \%(\alpha=0.01)$ confidence level. Furthermore, in order to check the accuracy of the developed model recovery test was conducted with spiking 2.5 and $5 \%(w / w)$ 
ethanol in randomly selected three real samples. The percentage recovery obtained ranges from $97-98 \%(w / w)$. The amount of ethanol determined by the proposed method was also compared with the reported method [23]. The obtained results showed that the two methods are comparable and did not show any significant difference at $99 \%(\alpha=0.01)$ confidence level.

Figure 4 shows the accuracy of the predicted results with the reference ones. Therefore, this confirms the model with few calibration set (12 samples) can be used in NIR for the quantification of ethanol in the distilled alcoholic beverages.

Attempt was also made to determine methanol, but it was not detected in the real samples by both the PLS-NIR and GC-FID methods.

\section{CONCLUSION}

In this study, partial least squares model of NIR was found as an alternative technique in the determination of ethanol in alcoholic beverages. The result obtained has a good agreement in case of synthetic and real samples with correlation coefficient $\left(\mathrm{R}^{2}\right)$ values of 0.999 and 0.06 RMSEP. Therefore, it can be concluded that the model is the promising alternative in the determination of ethanol in distilled alcoholic beverages.

\section{ACKNOWLEDGEMENTS}

The authors express their gratitude to the Department of Chemistry, Addis Ababa University, Ethiopia, for providing the laboratory facilities. Ayalew Debebe is thankful to the Haramaya University, Ethiopia, for sponsoring his study.

\section{REFERENCES}

1. Pérez-Ponce, A.; Rambla, F.J.; Garrigues, J.M.; Garrigues, S.; Guardia, M. Partial least squares-Fourier transform infrared spectrometric determination of methanol and ethanol by vapour-phase generation. Analyst 1998, 123, 1253-1258.

2. Siegel, M.B.; Naimi, T.S.; Cremeens, J.L.; Nelson, D.E. Alcoholic beverage preferences and associated drinking patterns and risk behaviors among high school youth. Am. J. Prev. Med. 2011, 40, 419-426.

3. Wang, M.-L.; Choong, Y.-M.; Su, N.-W.; Lee, M.-H. A rapid method for determination of ethanol in alcoholic beverages using capillary gas chromatography. J. Food Drug Anal. 2003, 11, 133-140.

4. Association of Official Analytical Chemists AOAC Official Method of Analysis Wine, 15th ed., in Official Methods of Analysis of AOAC International 739, AOAC International: USA; 1990.

5. Rotariu, L.; Bala, C.; Magearu, V. New potentiometric microbial biosensor for ethanol determination in alcoholic beverages. Anal. Chim. Acta 2004, 513, 119-123.

6. Ohura, H.; Imato, T.; Asano, Y.; Yamasaki, S.; Ishibashi, N. Potentiometric determination of ethanol in alcoholic beverages using a flow-injection analysis system equipped with a gas diffusion unit with a microporous poly(tetrafluoroethylene) membrane. Anal. Sci. 1990, 6, $541-545$.

7. Dyer, R.H. AOAC Official Methods of Analysis, 16th ed., Association of Official Analytical Chemists (AOAC): USA; 1995.

8. Sumbhate, S.; Nayak, S.; Goupale, D.; Tiwari, A.; Jadon, R.S. Colorimetric method for the estimation of ethanol in alcoholic-drinks. J. Anal. Tech. 2012, 1, 1-6.

9. Kuria, M.W.; Olando, Y. Alcohol dependence: Does the composition of the available beverages promote it. Open J. Psychiatry 2012, 2, 301-304. 
10. Chen, Z.; Yu, J.J.; Hibbert, D.B. Flow injection, amperometric determination of ethanol in wines after solid-phase extraction. Electrounalysis 1997, 9, 541-543.

11. Rangel, A.O.S.S.; Toth, I.V. Determination of ethanol in wines by flow injection spectrophotometry using gas-diffusion and an immobilized enzyme reactor. Am. J. Enon. Vitic. 1999, 50, 259-263.

12. Borges, S.S.; Frizzarin, R.M.; Reis, B.F. An automatic flow injection analysis procedure for photometric determination of ethanol in red wine without using a chromogenic reagent. Anal. Bioanal. Chem. 2006, 385, 197-202.

13. Nagarajan, R.; Mehrotra, R.; Bajaj, M.M. Quantitative analysis of methanol, an adulterant in alcoholic beverages using attenuated total reflectance spectroscopy, J. Sci. Ind. Res. India 2006, 65, 416-419.

14. Fletcher, P.J.; Van Staden, J.F. Determination of ethanol in distilled liquors using sequential injection analysis with spectrophotometric detection. Anal. Chim. Acta 2003, 499, 123-128.

15. Picque, D.; Lieben, P.; Corrieu, G.; Cantagrel, R.; Lablanquie, O.; Snakkers, G. Discrimination of cognacs and other distilled drinks by mid-infrared spectropscopy. J. Agric. Food Chem. 2006, 54, 5220-5226.

16. Lachenmeier, D.W. Rapid quality control of spirit drinks and beer using multivariate data analysis of Fourier transform infrared spectra. Food Chem. 2007, 101, 825-832.

17. Pontes, M.J.C.; Santos, S.R.B.; Araujo, M.C.U.; Almeida, L.F.; Lima, R.A.C.; Gaiao, E.N.; Souto, U.T.C.P. Classification of distilled alcoholic beverages and verification of adulteration by near infrared spectrometry. Food Res. Int. 2006, 39, 182-189.

18. Patz, C.-D.; Blieke, A.; Ristow, R.; Dietrich, H. Application of FT-MIR spectrometry in wine analysis. Anal. Chim. Acta 2004, 513, 81-89.

19. Fernandes, H.L.; Raimundo, J.I.M.; Pasquini, C.; Rohwedder, J.J.R. Simultaneous determination of methanol and ethanol in gasoline using NIR spectroscopy: Effect of gasoline composition.Talanta 2008, 75, 804-810.

20. Inon, F.A.; Garrigues, S.; Guardia, M. Combination of mid- and near-infrared spectroscopy for the determination of the quality properties of beers. Anal. Chim. Acta 2006, 571, 167174.

21. Mendes, L.S.; Oliveira, F.C.C.; Suarez, P.A.Z.; Rubim, J.C. Determination of ethanol in fuel ethanol and beverages by Fourier transform (FT)-near infrared and FT-Raman spectrometries. Anal. Chim. Acta 2003, 493, 219-231.

22. Nordon, A.; Mills, A.; Burn, R.T.; Cusick, F.M.; Littlejohn, D. Comparison of non-invasive NIR and Raman spectrometries for determination of alcohol content of spirits. Anal. Chim. Acta 2005, 548, 148-158.

23. Debebe, A.; Anberbir, A.; Redi-Abshiro, M.; Chandravanshi, B.S.; Asfaw, A.; Asfaw, N.; Retta, N. Alcohol determination in distilled alcoholic beverages by liquid phase Fourier transform mid-infrared and near-infrared spectrophotometers. Food Anal. Method. 2017, 10, 172-179.

24. Debebe, A.; Redi-Abshiro, M.; Chandravanshi, B.S. Non-destructive determination of ethanol levels in fermented alcoholic beverages using Fourier transform mid-infrared spectrometry. Chem. Cent. J. 2017, 11, 27. DOI: 10.1186/s13065-017-0257-5.

25. Yukihiro, O.; Fred, M.W.; Alfred, A.C. Near-Infrared Spectroscopy in Food Science and Technology, John Wiley and Sons: New York; 2007. 